\title{
Experiências com a docência: apresentando o campo de investigação
}

Fagner Carniel ${ }^{1}$; Samuel Costa ${ }^{2}$; Wesley Furriel $^{3}$

Impossível esconder a satisfação que me causou o convite de Hilton Costa para organizar este dossiê. Depois de alguns anos orientando o Estágio Supervisionado no curso de Ciências Sociais da Universidade Estadual de Maringá, fui surpreendido por um conjunto interessante de investigações a respeito do exercício da docência no magistério público do Paraná. Elas foram elaboradas por jovens estudantes que tive a sorte de encontrar nas disciplinas da licenciatura e que me ensinaram alguns caminhos criativos para lidar com a prática da pesquisa na formação de educadores e educadoras. Nesse sentido, apresentar seus artigos significa, para mim, relembrar a própria proposta que construímos ao longo daquele primeiro semestre de 2013: seguir os passos dos professores e professoras que atuam nas escolas da região, registrar suas ações, escutar o que esses sujeitos têm a dizer sobre a

\footnotetext{
${ }^{1}$ Professor do Departamento de Ciências Sociais da Universidade Estadual de Maringá.

${ }^{2}$ Graduado em Ciências Sociais pela Universidade Estadual de Maringá.

${ }^{3}$ Graduando em Ciências Sociais pela Universidade Estadual de Maringá.
} 
profissão, conhecer suas biografias e procurar interpretar a maneira como teceram os fios de suas carreiras.

Realmente não era pouca coisa. Estavam diante de trajetórias vividas por outras pessoas e precisavam objetivá-las a partir de um recorte que lhes permitisse certo controle do tema selecionado. Tal escolha, porém, costuma ser apenas o começo. O que conta mesmo é o estilo que nela se empreende; ou seja, essa capacidade singular com que cada um ou cada uma consegue delimitar sua análise, orientar sua reflexão e tornar consciente o processo que possibilitou a realização da pesquisa. Por isso, faço questão de ressaltar aqui minha admiração por esses alunos e alunas, pois souberam como se aproximar de experiências que não eram suas e, mesmo assim, se deixar tocar por elas, transformando-as em escritos sensíveis. São textos que nos falam de perspectivas sobre o ensino e de histórias de vida até então desconhecidas, ao mesmo tempo em que nos apresentam um novo pesquisador ou pesquisadora a cada problemática analisada.

$\mathrm{O}$ artigo que abre este dossiê, intitulado Práticas docentes em construção: considerações sobre performances e identidades de professores no espaço escolar, me parece introduzir bem a proposta de pensar a docência enquanto uma experiência plural que se constitui no cruzamento de biografias pessoais com trajetórias profissionais. Nele, Samuel Costa procura problematizar os discursos e as representações 
cotidianas que performatizam práticas sociais identificadas com o magistério público. $O$ papel das vivências e subjetividades na construção das identidades docentes também foi o tema selecionado por Raony Palicer, em Formação acadêmica, participação política e identidades profissionais - histórias de vida de professores de Sociologia em Maringá-PR. Neste artigo, o autor se debruça sobre duas biografias específicas, procurando demonstrar como determinados hábitos, ideologias, gostos e subjetividades concorrem para a definição de estilos sempre pessoais de ensino. Camila Galetti, em Empoderamento feminino e trajetória de vida: os modelos rígidos do "ser mulher", recoloca tal questão a partir do percurso de uma professora de sociologia, indicando a relevância das relações de gênero como um ângulo pertinente para o estudo das dinâmicas que configuram a profissionalização docente.

Em todos estes casos, as experiências relatadas pelos professores e professoras foram percebidas como acontecimentos que exigiram certa abertura, certa exposição de quem as escutou, transformando a prática da pesquisa em uma prova tão perigosa quanto apaixonante. Uma atividade que atravessava nossa superfície sensível deixando suas marcas, seus efeitos, e nos desafiando a repensar alguns dos principais dilemas, tensões e impasses que fazem parte do dia a dia dos professores e professoras da rede estadual de ensino. Tal inquietação 
levou Isadora Moraes, em A construção da indisciplina: um estudo exploratório sobre as possibilidades de compreensão da indisciplina escolar enquanto construção social, a questionar o modo como algumas normas de comportamento foram fixadas e significadas em um dos colégios de Maringá para constituir uma ideia de indisciplina escolar. Para isso, a autora mobiliza a teoria do desvio como uma chave interpretativa de suas experiências durante a disciplina de Estágio Supervisionado. Rafael Adílio, por sua vez, procurou travar um debate sobre os desafios da docência para quem trabalha em um regime temporário. Em seu artigo, A escola e as condições do trabalho docente: um retrato de Maringá, explora as condições de precarização do ensino público paranaense.

Paro por aqui, sem aprofundar o conteúdo desses artigos, pois não gostaria de prescrever ainda mais seus escritos com minha marca, atribuindo-lhes uma identidade, uma direção que talvez sobrecarregue seus textos com sentidos estranhos, impróprios ou demasiadamente "professorais". Aproveito esta oportunidade apenas para adiantar à leitora ou ao leitor de onde esses textos falam. Para tal tarefa, pedi auxílio a dois alunos, Samuel Costa e Wesley Furriel, com a intenção de situar o contexto mais geral das pesquisas realizadas e expor alguns indicadores que possam contribuir com a leitura. Isso porque todos os artigos exploram trajetórias profissionais e contextos escolares que 
estão situados nas cidades de Maringá e Sarandi - dois municípios localizados ao norte do estado do Paraná. Conforme o Censo Escolar de $2012^{4}$, Maringá reuniu cerca de 46 colégios de ensino médio (27 delas na rede pública e 19 na rede privada), abrigando aproximadamente 14.886 estudantes (10.961 na rede publica e 3925 na rede privada) e 654 docentes. Sarandi, por outro lado, contou com 08 colégios neste nível da educação básica (07 na rede pública e 01 na rede privada), somando um total de aproximadamente 3.118 matriculas e 186 docentes. No mapa 01 é possível observar a distribuição espacial desses colégios segundo o território de cada cidade.

4 Fonte: Ministério da Educação, Instituto Nacional de Estudos e Pesquisas Educacionais - INEP - Censo Educacional 2012. 


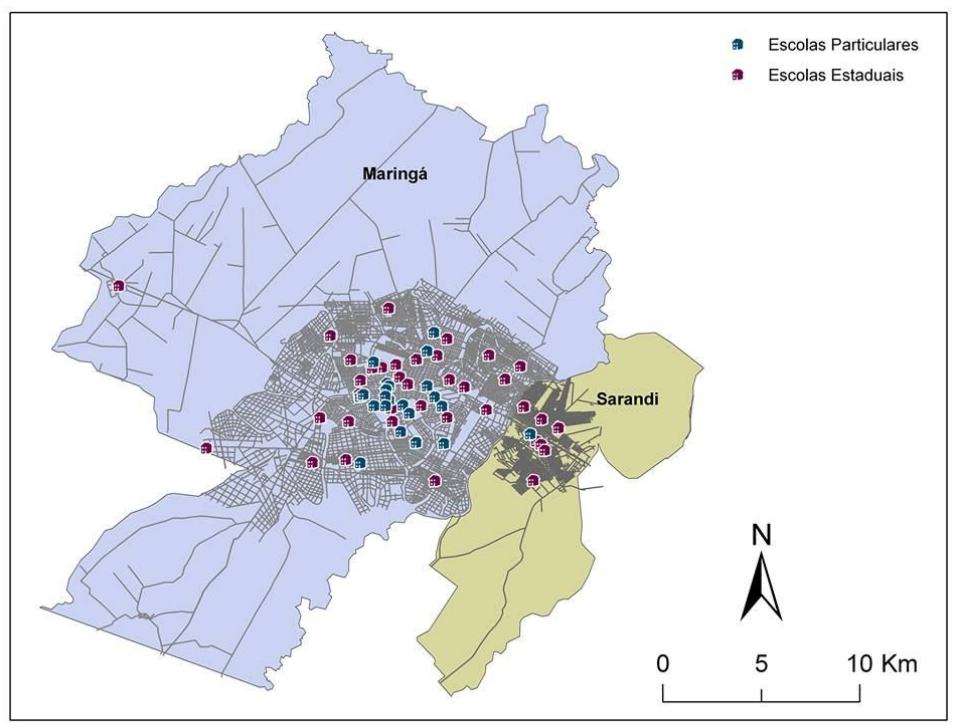

A partir da identificação dos colégios que serviram como pano de fundo para as investigações aqui apresentadas, decidimos aprofundar um pouco mais nossa análise com a intenção de também expor um perfil, certamente preliminar, dos principais atores atrizes que foram retratados pelos artigos. Estamos nos referindo aos professores e professoras formados em Ciências Sociais e que ministram a disciplina de Sociologia na rede escolar da região; afinal, direta ou indiretamente, as percepções, as trajetórias e as experiências acumuladas por tais profissionais representaram, em grande medida, o principal foco de atenção daqueles jovens pesquisadores e pesquisadoras que cursaram a licenciatura em Ciências Sociais da Universidade Estadual de Maringá 
no ano de 2013. Portanto, deste universo de 840 docentes nos municípios de Maringá e Sarandi, os artigos se concentraram em um número ainda menor de pessoas que atuaram em sua área de formação. A Tabela 01 indica que apenas $45 \%$ dos professores e professoras que ministraram a disciplina de Sociologia eram formadas em Ciências Sociais.

\begin{tabular}{|c|c|c|}
\hline \multicolumn{3}{|c|}{$\begin{array}{l}\text { Tabela } 01 \text { - Formação dos/das docentes que ministram } \\
\text { Sociologia }\end{array}$} \\
\hline & $\mathrm{F}$ & $\%$ \\
\hline Pedagogia & 14 & 19,44 \\
\hline Letras & 5 & 6,94 \\
\hline Ciências Biológicas & 1 & 1,39 \\
\hline Geografia & 2 & 2,78 \\
\hline História & 11 & 15,28 \\
\hline Comunicação Social & 1 & 1,39 \\
\hline Publicidade e Propaganda & 1 & 1,39 \\
\hline Ciências Naturais & 1 & 1,39 \\
\hline Matemática & 1 & 1,39 \\
\hline Ciências Sociais & 33 & 45,83 \\
\hline Filosofia & 2 & 2,78 \\
\hline Total & 72 & \\
\hline
\end{tabular}

Embora somente 33 docentes representem o perfil investigado pelos artigos, a Tabela 02 informa um total 54 professores e professoras formadas em Ciências Sociais. Deste contingente de profissionais, é significativo observar que a ampla maioria, cerca de $83,9 \%$, atua na rede pública de ensino e praticamente a metade dessas pessoas teve seu contrato efetivado em regime temporário de serviços por meio de um processo seletivo simplificado. 


\begin{tabular}{|c|c|c|}
\hline \multicolumn{3}{|c|}{ Dependência administrativa } \\
\hline & $\mathrm{F}$ & $\%$ \\
\hline Público & 44 & 81,48 \\
\hline Privada & 8 & 14,81 \\
\hline Ambos & 2 & 3,70 \\
\hline \multicolumn{3}{|c|}{ Situação funcional (apenas para docente de escola pública) } \\
\hline & $\mathrm{F}$ & $\%$ \\
\hline Concursado/efetivo/estável & 20 & 43,5 \\
\hline Contrato temporário & 26 & 56,5 \\
\hline
\end{tabular}

Fonte: Censo escolar 2012

Ainda que os professores e professoras formadas em Ciências Sociais atuem na disciplina de Sociologia, é necessário observar que também podem ter ministrado outras disciplinas - o que explica, em alguma medida, o descompasso entre os números apresentados anteriormente. Na Tabela 03 temos a distribuição de docentes com formação na área segundo a disciplina ministrada ${ }^{5}$. São 11 disciplinas diferentes, o que pode ser compreendido por dois fatores: a existência de docentes com mais de uma graduação; e a existência de docentes que atuam fora de sua área de formação.

\footnotetext{
${ }^{5}$ No que se refere a Tabela 03, ressaltamos que um mesmo docente pode atuar em mais de uma disciplina da educação básica. Por isso, de um número de 54 docentes formados em Ciências Sociais, localizamos 78 inscrições em disciplinas.
} 


\begin{tabular}{|c|c|c|}
\hline & $\mathrm{F}$ & $\%$ \\
\hline Matemática & 5 & 6,41 \\
\hline Ciências & 5 & 6,41 \\
\hline Lingua/Literatura Portuguesa & 7 & 8,97 \\
\hline Artes & 3 & 3,85 \\
\hline Educação Fisica & 1 & 1,28 \\
\hline História & 7 & 8,97 \\
\hline Geografia & 7 & 8,97 \\
\hline Filosofia & 3 & 3,85 \\
\hline Ensino Religioso & 6 & 7,69 \\
\hline Sociologia & 33 & 42,31 \\
\hline Disciplinas profissionalizantes & 1 & 1,28 \\
\hline Total & 78 & 100,00 \\
\hline
\end{tabular}

Por fim, na Tabela 04, procuramos informar certas características sócio-demográficas desse grupo de docentes para que os leitores e leitoras deste dossiê se aproximem dos perfis profissionais investigados ao longo das páginas que seguirão. Isso porque a escolha das pessoas entrevistadas também pode revelar algumas das questões que ocuparam a imaginação dos autores e autoras destes artigos. A intenção não é realizar nenhuma análise destes dados estatísticos, mas somente anunciá-los como uma forma de introduzir o cenário que circunscreveu estes trabalhos e seus modos particulares de problematizar as experiências contingentes da docência em nossa região. 


\begin{tabular}{|c|c|c|}
\hline \multicolumn{3}{|c|}{ Sexo } \\
\hline & $\overline{\mathrm{F}}$ & $\%$ \\
\hline Feminino & 36 & 64,3 \\
\hline Masculino & 20 & 35,7 \\
\hline \multicolumn{3}{|c|}{ Idade } \\
\hline $16-25$ & \begin{tabular}{l|l}
6 \\
\end{tabular} & 10,7 \\
\hline $26-35$ & 23 & 41,1 \\
\hline $36-50$ & 17 & 30,4 \\
\hline mais de 50 & 10 & 17,9 \\
\hline \multicolumn{3}{|c|}{ Cor } \\
\hline Branca & \begin{tabular}{l|l}
41 \\
\end{tabular} & 80,4 \\
\hline Preta & 6 & 11,8 \\
\hline Parda & 3 & 5,9 \\
\hline Amarela & 1 & 2,0 \\
\hline Não declarada & 5 & - \\
\hline
\end{tabular}

Fonte: Censo escolar 2012

Não poderíamos finalizar esta apresentação sem antes registrar nossos profundos agradecimentos aos professores e professoras da rede escolar de Maringá que nos acompanharam neste processo. Mais do que suas salas de aula, estes profissionais ofereceram suas histórias, suas perspectivas, suas maneiras de ensinar e de significar a educação pública. Espero que agora, diante dos artigos aqui reunidos, possam aproveitar pelo menos um pouco de todas as experiências que compartilharam 